\title{
Potential energy recovery from LNG regasification in LNG-fueled ships
}

\author{
Gianluca Pasini, Andrea Baccioli ${ }^{*}$,Lorenzo Ferrari and Umberto Desideri \\ Department of Energy, Systems, Territory and Constructions Engineering, University of Pisa, 56122 \\ Largo L. Lazzarino, Pisa, Italy
}

\begin{abstract}
Recent regulatory initiatives regarding ships emissions raised the interest of maritime operators on cleaner fuels. The International Maritime Organization (IMO) with Annex VI of the International Convention for the Prevention of Pollution from Ships (MARPOL) set strict limits on $\mathrm{SO}_{\mathrm{x}}, \mathrm{NO}_{\mathrm{x}}$ and $\mathrm{CO}_{2}$ emissions. Many studies have been carried out to increase engine efficiency based on waste heat recovery such as ORC or turbocompounding. Using LNG as a fuel opens new opportunities in this prospect. In this study, an energy recovery from LNG regasification process, through a dedicated and optimized cycle, is investigated. The system is made of an open supercritical Rankine cycle performed before engine injection and exploiting LNG as a working fluid. Results showed the influence of the maximum temperature and pressure of the cycle on the system performance. A maximum power recovery up to $2.2 \%$ of main engine power was found.
\end{abstract}

\section{Introduction}

Nowadays, most of the vessels are fueled with Heavy Fuel Oil (HFO) for economic reasons. HFOs are cost effective, but they contain high levels of impurities, thus producing significant amounts of emissions such as nitrogen oxides $\left(\mathrm{NO}_{\mathrm{x}}\right)$, sulphur oxides $\left(\mathrm{SO}_{\mathrm{x}}\right)$, carbon dioxide $\left(\mathrm{CO}_{2}\right)$ and carbon monoxide $(\mathrm{CO})$.

The general trend of global and local legislations is leaning towards tighter regulations and higher standards of compliance with tougher emission limitations. Many countries demanded actions to limit both air and sea emissions from the marine sector (i.e. Emission Control Areas, ECAs). The International Maritime Organization (IMO) with Annex VI of the International Convention for the Prevention of Pollution from Ships (MARPOL) set strictly limits on $\mathrm{SO}_{\mathrm{x}}$ and $\mathrm{NO}_{\mathrm{x}}$ emissions from the ship engines. In April 2018, IMO's Marine Environment Protection Committee (MEPC) adopted an initial strategy for the reduction of greenhouse gas emissions from ships with the intent to reduce them rapidly [1].

These new targets are achieved by using complex and expensive emission control systems that retrofit HFO engines [2] or by adopting cleaner fuels such as Maritime Diesel Oil (MDO) or Liquified Natural Gas (LNG) [3]. By using LNG, not only $\mathrm{SO}_{\mathrm{x}}$ and particulate matter emissions are reduced but also those of $\mathrm{NO}_{\mathrm{x}}$ and $\mathrm{CO}_{2}$. In addition, $\mathrm{LNG}$ price during the last

\footnotetext{
*Corresponding author: andrea.baccioli@unipi.it
} 
years has been lower than MDO and HFO thus leading to an economic attractiveness of LNG as a marine fuel.

Many studies can be found in the literature that investigates the use of LNG as a fuel for ship propulsion [4-5]. Other authors analyzed the maritime traffic and made a statistical analysis that determined the benefits of using LNG [6]. Other authors focused on the technical and life cycle analysis of a propulsion system based on LNG and found an efficiency increase of $2 \%$ and an emission reduction of $80 \%$ for $\mathrm{NO}_{\mathrm{x}}$ and $100 \%$ for $\mathrm{SO}_{\mathrm{x}}$ [7].

About $50 \%$ of the total thermal energy of an internal combustion engine (ICE) is released to the ambient. One of the most studied technologies to increase propulsion system efficiency is the waste heat recovery (WHR) [8]. Waste heat can be used for several purposes such as refrigeration, desalination or power generation [9-14]. Regarding ICEs, there are different attractive sources of waste thermal energy that might be exploited: exhaust gases, cooling water, oil cooling and turbocharger intercooler [15].

In the case of LNG fueled ships, the recovery of cryogenic energy can play an important role in the efficiency increase of the generation system. In this study, an engine operating with LNG was considered. The traditional LNG regasification process, normally used to produce natural gas for engine use, was revised to produce additional power. In more detail, the process was arranged to operate as a supercritical Rankine cycle using natural gas as working fluid. A wide overview of available technologies for regasification in big onshore terminals are available in the literature [16] but only a few of them could be applied in engine applications.

\section{Case study}

The study has been carried out by considering a 12-cylinder marine engine (Wärtsilä 12V50DF) operating in Gas mode operation (Table 1) [17]. Wärtsilä engines of 50DF family can be run on either LNG, Light Fuel Oil (LFO) or HFO and are designed to provide the same output regardless of the fuel.

Table 1. Engine Specifications.

\begin{tabular}{|c|c|}
\hline Parameter & Value \\
\hline Engine output @ $514 \mathrm{rpm}[\mathrm{kW}]$ & 11700 \\
\hline Exhaust gas flow at full load $[\mathrm{kg} / \mathrm{s}]$ & 19.0 \\
\hline Temperature after turbocharger $\left[{ }^{\circ} \mathrm{C}\right]$ & 382 \\
\hline Gas consumption at full load $[\mathrm{kg} / \mathrm{h}]$ & 1722 \\
\hline Minimum gas pressure to engine $[\mathrm{bar}]$ & 5.92 \\
\hline Gas temperature to the engine $\left[{ }^{\circ} \mathrm{C}\right]$ & $0-60$ \\
\hline
\end{tabular}

In the proposed arrangement (Figure 1), LNG from a tank (Type A tank, @ 1.1 barA and $-160{ }^{\circ} \mathrm{C}$ ) was pumped at high pressure by a cryogenic pump and then sent to two heat exchangers for gasification. In the first heat exchanger (EX1), natural gas is warmed up to $15^{\circ} \mathrm{C}$. This cooling power may be recovered for cooling purposes. In the second heat exchanger (EX2), the natural gas is heated up by an intermediate heat transfer fluid and then sent to the high-pressure turbine. The turbine inlet temperature is a function of the heat source recovered (seawater, engine jacket water, thermal cascades or engine exhaust gas). After the turbine, if the temperature of natural gas is below $-15^{\circ} \mathrm{C}$, additional cooling power may be provided to the system (EX3). Afterwards, natural gas is heated up in another heat exchanger (EX4) and then expanded in a low-pressure turbine. After this turbine, depending on the temperature, the fluid may still provide some useful energy for cooling (EX5). Before the injection into the engine, the gas temperature is regulated in a seawater heat exchanger (EX6). 


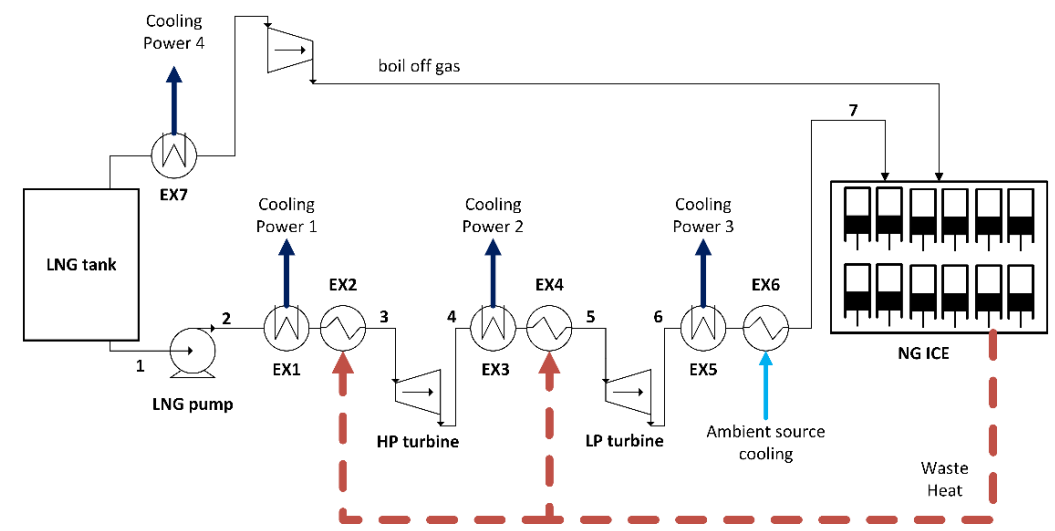

Fig. 1. Proposed system, layout

Boil-off gas (BOG), from the fuel tank was warmed up in the heat exchanger EX7 (energy may be recovered for cooling), sent to a compressor and injected. The performance of this arrangement was simulated in a wide range of maximum cycle pressure (from 50 to 300 bar) and temperature (from $20^{\circ} \mathrm{C}$ to $250^{\circ} \mathrm{C}$ ) corresponding to different system complexities and waste heat thermal sources.

\section{Methodology}

A VBA model based on CoolProp equation of state for LNG thermo-physical properties was developed to analyze the performance of the system. For the sake of simplicity, LNG composition was considered as $100 \%$ of methane. The amount of BOG depends on the volume of the cryogenic tank and was estimated by linearly extrapolating data reported in [16] by considering a tank volume of $490 \mathrm{~m}^{3}$ (Eq. 1).

$$
\dot{m}_{B O G}=7.42 \cdot 10^{-6} \cdot V_{\text {tank }}+0.025
$$

where $\dot{m}_{B O G}$ is the BOG mass flow rate in $\mathrm{kg} / \mathrm{s}$ and $V_{\text {tank }}$ is the tank volume in $\mathrm{m}^{3}$. The power requested by the $\mathrm{BOG}$ compressor was estimated as:

$$
\dot{W}_{B O G}=\frac{\dot{m}_{B O G} \cdot \Delta h_{i s, c}}{\eta_{i s, c}}
$$

where $\dot{m}_{B O G}$ is the BOG mass flow rate, $\Delta h_{i s, c}$ is the isentropic enthalpy variation and $\eta_{i s, c}$ is the isentropic efficiency of the BOG compressor, assumed as $70 \%$. The pumping power requested by the cryogenic pump was estimated as:

$$
\dot{W}_{p}=\frac{\dot{m}_{L N G} \cdot \Delta P}{\rho \cdot \eta_{i s, p}}
$$

where $\dot{m}_{L N G}$ is the LNG mass flow rate, $\Delta P$ is the pressure difference between the highest system pressure (point 2) and the tank, $\rho$ is LNG density and $\eta_{i s, p}$ is the isentropic efficiency of the pump, assumed as 70\%. The same temperature in 3 and 5 was assumed in the analysis. Turbines power was evaluated as:

$$
\dot{W}_{t}=\dot{m}_{L N G} \cdot \Delta h_{i s, t} \cdot \eta_{i s, t}
$$


where $\Delta h_{i s, t}$ is the isentropic enthalpy drop and $\eta_{i s, t}$ is the isentropic efficiency of the turbines, assumed as $80 \%$. The net power output takes into account the contributions of all devices and can be calculated as:

$$
\dot{W}_{N E T}=\dot{W}_{t, H P}+\dot{W}_{t, L P}-\dot{W}_{p}-\dot{W}_{B O G}
$$

where $\dot{W}_{t, H P}$ and $\dot{W}_{t, L P}$ are respectively the power output of the high-pressure and lowpressure turbine. The cooling capacity was estimated by considering the warming up of LNG or cold natural gas after the expansions and BOG up to a temperature of $-15^{\circ} \mathrm{C}$. A pneumatic coefficient of 0.98 was considered for each heat exchanger to take into account pressure drops.

\section{Results}

For a fixed total mass flow rate of LNG (with constant BOG), representing the engine consumption at full load, a sensitivity analysis to find the condition in which the net output power of the proposed system is maximized has been carried out. In Figure 2, the optimal pressure ratio of the two turbines, for several maximum pressure and temperature, is reported.

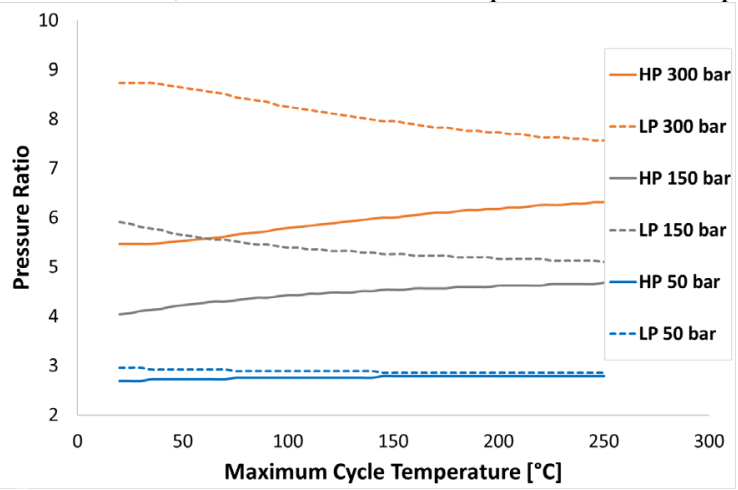

Fig. 2. Optimal pressure ratio for some combinations of maximum pressure and temperatures.

Figure 2 shows that there is a great difference between the HP and LP turbine pressure ratios, especially when the cycle pressure is high and the turbine inlet temperature is low. This behavior depends on the thermo-physical properties of methane, which are far from those of an ideal gas in these conditions. When the pressure decreases (e.g. when the maximum cycle pressure is 50 bar) the pressure ratio of HP and LP turbines are similar and almost insensitive to maximum cycle temperature $\left(\beta_{\mathrm{HP}}=\beta_{\mathrm{LP}}=\sqrt{ } \beta_{\text {тот }}\right)$. For higher pressures (e.g. $150 \mathrm{bar}$ and 300 bar) the influence of real gas properties leads to higher pressure ratio of LP turbine when the maximum temperature decreases.

In Figure 3, the net power output for three cycle maximum pressures is reported. It is worth to notice that the influence of pressure is negligible on power output when maximum cycle temperature is low $\left(50^{\circ} \mathrm{C}\right)$. In this case, a value of pressure that maximized the system power output exists. By increasing the temperature of the cycle, the pressure has a large influence on the system power output, up to about 100-120 bar of maximum cycle pressure, and then its benefic effect is sharply reduced. The reduction in cycle power output with a pressure increase, especially at high temperature, is due to the increase of pump power absorption.

The back-work ratio (Figure 4 left), i.e. the ratio between the pump absorption and the net power output of the cycle is a parameter that allows the estimation of the impact of pump absorption on cycle performance [19]. 


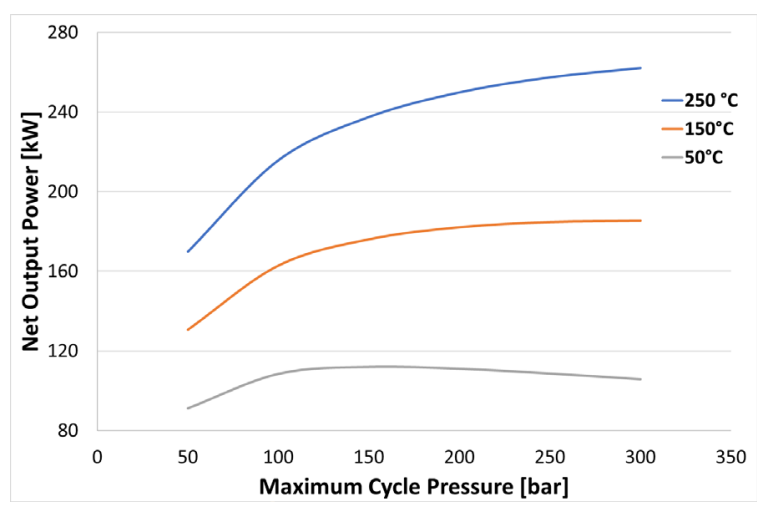

Fig. 3. Net output Power as a function of maximum pressure for 3 maximum temperatures.

The back-work ratio is very high when the cycle temperature is low and pressure is high. As an example, when the pressure is 300 bar and the maximum cycle temperature is $20{ }^{\circ} \mathrm{C}$, the pump consumes about $58 \%$ of the net power produced. This value decreases by increasing the maximum cycle temperature and reducing the maximum pressure. As a summary, in Figure 4 right, the Net Output Power output and the available Cooling Power are reported for all the simulated cases.
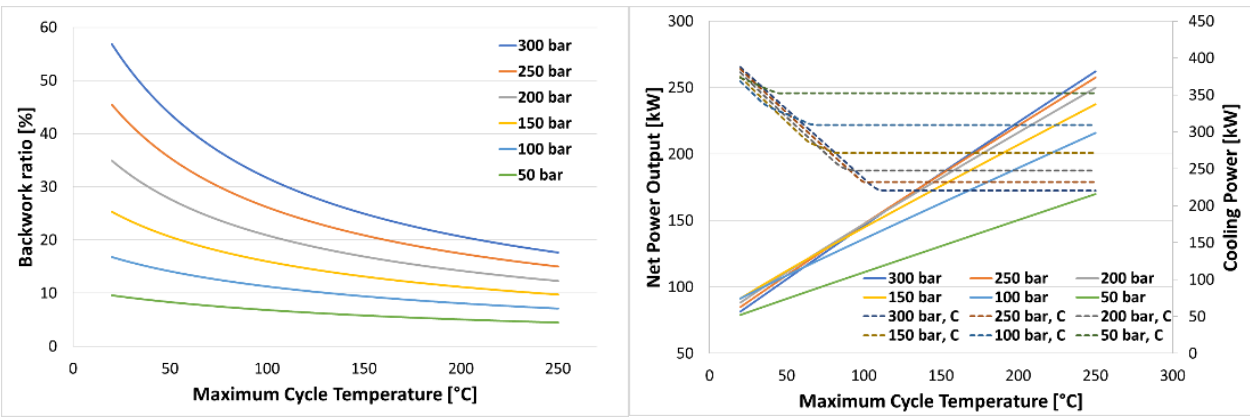

Fig. 4. Net Power and Cooling Power Output, all cases.

Due to the strong influence of pumping absorption, only small benefits in terms of net power output are achieved by increasing the maximum pressure over 150 bar and only if the maximum temperature is above $100^{\circ} \mathrm{C}$. Beyond 200 bar the gain in power output, even at the highest temperature, is minimal. As a summary, the maximum gain in power output is in the range between 0.7 and $2.2 \%$ of the engine power output, by varying the maximum cycle temperature from $20{ }^{\circ} \mathrm{C}$ to $250{ }^{\circ} \mathrm{C}$. Maximum cooling powers are plotted with dashed lines in Figure 4, right. These values are the cooling power achievable if four different cooling circuits are employed (equal to the number of possible cooling extractions). The horizontal portion of the trends is the contribution of the cooling power 1 and 4 in Figure 1. By increasing the pressure, the cooling power decreases because of the contribution of the pump (point 2 in Figure 1). Cooling power 2 and 3 are highly affected by the maximum cycle temperature and becomes null when the cycle maximum temperature increases.

\section{Conclusions}

This study is focused on thermodynamic analysis of a dual pressure direct expansion cycle of LNG before injection in an internal combustion engine for naval purposes. Such system 
might operate also as a bottoming unit of other WHR systems. In more detail, the process was arranged to operate as a supercritical Rankine cycle using natural gas as working fluid. Simulations have been carried out for different maximum cycle pressure and temperature (50-300 bar and $20-250{ }^{\circ} \mathrm{C}$ ) to optimize the expansion ratio and maximize the power output. Results showed that up to $262 \mathrm{~kW}$ could be recovered (2.2\% of main engine power) by using only a portion of the total waste heat. The influence of the maximum cycle pressure turned out to be small in comparison to that of the maximum cycle temperature: an increase of the pressure above 150 bar leads to small benefits and only for temperatures above $100{ }^{\circ} \mathrm{C}$. The proposed system allows the recovery of free cooling power for onboard demand, such as air condition, food conservation or even for additional engine enhancement (intake air cooling). Economic and technical issues, also concerning current regulatory framework, will be carefully analyzed in future developments.

\section{References}

1. International Maritime Organization (IMO) http://www.imo.org/en/MediaCentre/HotTopics/GHG/Pages/default.aspxv (last access 07/01/19)

2. F. Burel, R. Taccani, N. Zuliani, Improving sustainability of maritime transport through utilization of liquefied natural gas (LNG) for propulsion. Energy 2013;57:412-20.

3. C. Lin, Strategies for promoting biodiesel use in marine vessels. Mar Policy 2013;40(1):84-90.

4. B. Curt, Marine transportation of LNG, presentation at the Intertanko conference March 29, 2004.

5. A.B. Smith, Gas fuelled ships: fundamentals, benefits classification \& operational issues. In: Proceedings of the first gas fuelled ships conference, Hamburg, Germany 2010.

6. O. Schinas, M. Butler Feasibility and commercial considerations of LNG-fueled ships. Ocean Engineering Volume 122, 1 August 2016, Pages 84-96

7. G.A. Livanos, G. Theotokatos., D.N. Pagonis, 2014. Techno-economic investigation of alternative propulsion plants for ferries and roro ships. Energy Conversion Management 79,640-651.

8. K. Senary, A. Tawfik, E. Hegazy, A. Ali, Development of a waste heat recovery system onboard LNG carrier to meet IMO regulations Alexandria Engineering Journal Volume 55, Issue 3, September 2016, Pages 1951-1960.

9. D.V. Singh, E. Pedersen, A review of waste heat recovery technologies for maritime applications, Energy Conversion Management 111 (2016) 315-328.

10. G. Shu, Y. Liang, H. Wei, H. Tian, J. Zhao, L. Liu, A review of waste heat recovery on two-stroke IC engine aboard ships, Renew. Sustain. Energy Rev. 19 (2013) 385-401.

11. S. Frigo, G. Pasini, S. Marelli, et al.: Numerical evaluation of an electric turbo compound for SI engines', SAE Technical Paper 2014-32-0013, (2014)

12. G. Pasini, S. Frigo, S. Marelli, Numerical comparison of an electric turbo compound applied to a SI and a CI engine'. Proc. ASME ICEF2015, Houston, TX

13. G. Pasini, G. Lutzemberger, S. Frigo et al.: 'Evaluation of an electric turbo compound system for SI engines: a numerical approach', Applied Energy, (2016), 162, pp. 527-540

14. A. Baccioli, M. Antonelli, U. Desideri, A. Grossi, Thermodynamic and economic analysis of the integration of Organic Rankine Cycle and Multi-Effect Distillation in waste-heat recovery applications, Energy. 161 (2018) 456-469.

15. S. Nadaf, P. Gangavati, A review on waste heat recovery and utilization from diesel engines, Int. J. Adv. Eng. Technol. 5 (2014) 31-39.

16. I. Szczygiel, Z. Bulinski Overview of the liquid natural gas (LNG) regasification technologies with the special focus on the Prof. Szargut's impact Energy 165 (2018) 999-1008

17. S. Kochunni, K. Chowdhury, LNG boil-off gas reliquefaction by Brayton refrigeration system Part 1: Exergy analysis and design of the basic configuration, Energy. 176 (2019) 753-764.

18. Wärtsilä 50DF Product Guide https://www.wartsila.com/products/marine-oil-gas/enginesgenerating-sets/dual-fuel-engines/wartsila-50df (last access 07/01/19)

19. A. Baccioli, M. Antonelli, U. Desideri, Technical and economic analysis of organic flash regenerative cycles (OFRCs) for low temperature waste heat recovery, Applied Energy. 199 (2017) 69-87. 